\title{
Effect of Dominant Hand Paralysis on Quality of Life in Patients With Subacute Stroke
}

\author{
Hyeon Uk Nam, $\mathrm{MD}^{1}$, Jin Seok Huh, $\mathrm{MD}^{1}$, Ji Na Yoo, $\mathrm{MD}^{1}$, Jong Moon Hwang, MD ${ }^{1}$, \\ Byung Joo Lee, $\mathrm{MD}^{1}$, Yu-Sun Min, $\mathrm{MD}^{2}$, Chul-Hyun Kim, $\mathrm{MD}^{1}$, Tae-Du Jung, $\mathrm{MD}^{1,2}$ \\ ${ }^{1}$ Department of Rehabilitation Medicine, Kyungpook National University College of Medicine, Daegu; \\ ${ }^{2}$ Department of Rehabilitation Medicine, Kyungpook National University Hospital, Daegu, Korea
}

Objective To evaluate the degree to which the paralysis of a dominant hand affects quality of life (QOL) in patients with subacute stroke.

Methods We recruited 75 patients with subacute hemiplegic stroke. Patients were divided into two groups according to the location of the lesion and the side of the dominant hand. Group 1 consisted of patients whose strokes affected the dominant hand (i.e., right hemiplegia and right dominant hand or left hemiplegia and left dominant hand). Group 2 consisted of patients whose strokes affected the non-dominant hand (i.e., left hemiplegia and right dominant hand or right hemiplegia and left dominant hand). The primary outcome measure was the Short-Form 36-Item Health Survey (SF-36), which was used to evaluate health-related QOL. Secondary outcomes were scores on the Modified Barthel Index (MBI) and Beck Depression Inventory (BDI).

Results We did not find any statistically significant differences between the groups in any SF-36 domain including the summaries of physical and mental component. Similarly, the MBI and BDI scores were not significantly different between the groups.

Conclusion The effect of paralysis on the dominant hand and QOL in patients with subacute stroke was not significantly different from the effect of paralysis on the non-dominant hand.

Keywords Dominance, Quality of life, Stroke

\section{INTRODUCTION}

Stroke is a serious condition associated with a high

Received March 12, 2014; Accepted May 12, 2014

Corresponding author: Tae-Du Jung

Department of Rehabilitation Medicine, Kyungpook National University College of Medicine, 130 Dongduk-ro, Jung-gu, Daegu 700-721, Korea

Tel: +82-53-200-5311, Fax: +82-53-423-0389, E-mail: teeed0522@ hanmail.net

(c) This is an open-access article distributed under the terms of the Creative Commons Attribution Non-Commercial License (http://creativecommons. org/licenses/by-nc/3.0) which permits unrestricted noncommercial use, distribution, and reproduction in any medium, provided the original work is properly cited.

Copyright $\odot 2014$ by Korean Academy of Rehabilitation Medicine mortality rate and severe disability [1]. Social functions, such as self-management and communication, are generally reduced in stroke patients, and many reports showed results of poor quality of life (QOL) [1,2]. Several studies have found that poor daily function decreases QOL and satisfaction levels in stroke patients [3]; and Pyun et al. [4] noted that improving QOL was the primary objective of rehabilitation in stroke patients.

Hand dominance refers to a hand preference when performing a task [5]. Hand dominance is an important factor in the performance of motor skills, because the dominant hand is used for many daily and recreational activities [6,7]. The speed, precision, and coordination 
of the dominant hand are superior to those of the nondominant hand, which may stem from motor programs and skills developed through extensive practice and experience associated with the use of dominant hand [7-10].

A stroke involving the dominant hand may affect the patient's ability to perform daily tasks. In fact, activities of daily living (ADL) that require the use of upper limbs are seriously limited in $\mathbf{8 0 \%}$ of the stroke patients $[7,11]$. Spaulding et al. [12] administered the Jebsen Hand Function Test (JHFT) to 50 patients with hemiplegia. They found that participants in the study demonstrated significantly slower performance on all items of the test for both non-paretic and paretic hands, when the scores were compared to the previously published norms. Furthermore, right-handed patients with the left hemiplegia performed all subtests more slowly when using the involved hand, compared to those with the right hemiplegia. However, performance with the non-involved hand did not show significant difference between the left and the right hemiplegic groups on any subtest, with the exception of the writing subtest. Laufer et al. [13] examined time-related changes in motor performance of daily tasks of the upper extremity ipsilateral to the side of lesion, in poststroke hemiparetic patients. They found that left hands of patients with an intact right cerebral hemisphere showed more improvement compared to the patients with the right hand and the intact left cerebral hemisphere.

There are many studies about factors affecting QOL in stroke patients [14]. ADL and depression are wellknown to be the major factors affecting QOL after stroke [4]. However, no studies have investigated whether loss of function in the dominant hand affects QOL. Thus, we investigated the effect of paralysis on the dominant hand and QOL in patients with subacute stroke.

\section{MATERIALS AND METHODS}

\section{Subjects and methods}

Patients who were diagnosed with stroke in the Department of Rehabilitation Medicine between March 2009 and May 2013 were recruited for the study. A flow chart of the participant selection process is shown in Fig. 1.

Inclusion criteria were as follows: 1) within 3 months of stroke onset, 2) chief complaint of hemiparesis, and 3) first episode of unilateral stroke. Exclusion criteria were as follows: 1) uncertain which hand was dominant according to the Edinburgh Handedness Inventory (EHI), 2) cognitive impairment with less than 24 points on the Mini-Mental State Examination-Korean version (MMSEK), 3) cerebellar lesion, 4) lesion in both hemispheres, and 5) subarachnoid hemorrhage.

The patients were divided into two groups according to the location of the impairment and the side of the dominant hand. Group 1 consisted of patients whose lesion was on the same side as the dominant hand (right hemiplegia with right dominant hand or left hemiplegia with left dominant hand), and group 2 included patients whose lesion was on the side opposite to the dominant hand (left hemiplegia with right dominant hand or right hemiplegia patients with left dominant hand).

We used the EHI, a widely used test of handedness, to identify each patient's dominant hand [15]. The EHI consists of the following 10 items: writing; drawing; throwing; use of scissors, toothbrush, knife (without fork),

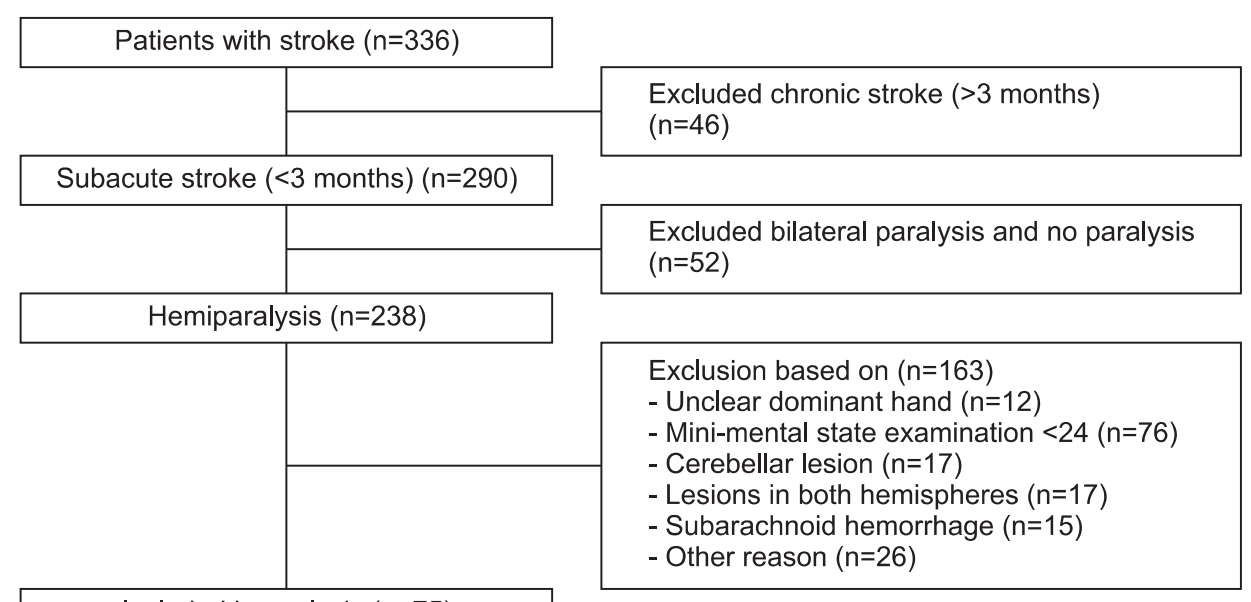

Included in analysis $(n=75)$
Fig. 1. Flow chart of the patient selection process. 
spoon, and broom (upper hand); striking a match; and opening a box. The subjects were instructed to indicate the strength of their hand preference for each of the 10 items, by putting one or two ticks in the right or left hand column or one tick in each column if they were indifferent about that item. The EHI laterality quotient score ranges from +100 (totally right handed) to -100 (totally left handed).

The present research was approved by the Institutional Review Board of Kyungpook National University Hospital (No. 2014-01-016).

\section{Outcome measurements}

\section{Primary outcome measure}

Short-Form 36-Item Health Survey (SF-36): The SF-36 is a questionnaire that assesses health-related quality of life (HRQOL); it has been used extensively in clinical and epidemiological research and in health service studies. The SF-36 is a widely used, generic, patient-reported, measure of health status. The survey comprises of the following 8 health subdomains: physical functioning (PF), role physical (RP), bodily pain (BP), general health (GH), vitality (VT), social functioning (SF), role emotional (RE), and mental health (MH). The PF, RP, BP, and GH scales are highly correlated with the physical component and are used to calculate the physical component summary (PCS). The VT, SF, RE, and MH scales are highly correlated with the mental component and are used to calculate the mental component summary (MCS) [16-18]. We used the Korean version of SF-36, which has been proven to be reliable and valid [16].

The SF-36 forms were completed upon the admission to the Department of Rehabilitation Medicine. The questionnaires were evaluated by rehabilitation medicine physicians who were not involved in our study.

\section{Secondary outcome measurements}

Modified Barthel Index (MBI) and Beck Depression Inventory (BDI): ADL was evaluated using the Korean version of the MBI (K-MBI) developed by Jung et al. [19] in 2007. The MBI consists of the following 10 items: personal hygiene, bathing, feeding, toileting, stair climbing, dressing, bowel control, bladder control, ambulation or wheelchair, and chair-bed transfer. The scores range from 0 indicating inability to perform to 100 indicating complete independence in performing self-care. The MBI scores were rated as follows: complete dependence (total scores of 0-20); severe dependence (21-60); moderate dependence (61-90); and slight dependence (91-99) [20]. The MBI is widely used throughout the world because it is reliable, valid, and free of royalty and copyright [21].

The BDI is a widely used self-report scale that measures the severity of depression. The BDI was developed to ascertain the type and degree of depression based on the symptoms [22]. The questionnaire contains 21 items assessing emotional, cognitive, motivational, physiological, and other symptoms. Each item consists of four statements describing increasing intensities of depression. The items are rated on a scale from 0 to 3 , reflecting feelings the participants have had over the past week. Possible scores range from 0 to 63 and higher scores indicate more severe depressive symptomatology [22]. The Korean version of the BDI has been standardized, and it is found to be reliable and valid [23]. The BDI has high reliability and alpha coefficient values, and it established construct validity [22]. We divided the severity of depression into two groups: normal (total score, $0-13$ ) and mild to severe depression (total score, 14-63) [24].

\section{Statistical analysis}

All statistical tests were conducted using the SPSS for Windows ver. 19 (SPSS Inc., Chicago, IL, USA). The chisquare test and independent t-tests were used to compare between-group baseline characteristics and SF-36, MBI, and BDI scores. A p-value $<0.05$ was deemed statistically significant.

\section{RESULTS}

\section{General characteristics}

Our study included 75 patients with subacute stroke. Among them, 31 patients ( 17 males and 14 females; mean age, $58.16 \pm 16.77$ years; time since onset of stroke, $3.63 \pm 4.87$ weeks) had their dominant hands paralyzed, and 44 patients (20 males and 24 females; mean age, $63.66 \pm 14.16$ years; time since onset of stroke, $3.57 \pm 3.43$ weeks) had their non-dominant hand paralyzed. The dominant-hand group (group 1) included 4 left and 27 right hands, and the non-dominant-hand group (group 2) included 3 left and 41 right hands.

No statistically significant differences between the groups were found for the following factors: age, sex, lesion location, type of stroke, hemorrhage volume, duration of disease, MMSE-K, Berg Balance Scale, National 
Table 1. Characteristics of patients with dominant- and non-dominant-hand paralysis following stroke

\begin{tabular}{|c|c|c|c|}
\hline Characteristic & $\begin{array}{l}\text { Dominant-hand } \\
\text { paralysis }(n=31)\end{array}$ & $\begin{array}{l}\text { Non-dominant-hand } \\
\text { paralysis }(n=44)\end{array}$ & p-value \\
\hline Age (yr) & $58.16 \pm 16.77$ & $63.66 \pm 14.16$ & 0.129 \\
\hline Gender (male:female) & $17: 14$ & $20: 24$ & 0.423 \\
\hline Lesion location (supratentorial:infratentorial) & $21: 10$ & $37: 7$ & 0.096 \\
\hline Type of stroke (infarct:hemorrhage) & $23: 8$ & $34: 10$ & 0.758 \\
\hline Hemorrhage volume (mL) & $20.93 \pm 11.91$ & $33.94 \pm 21.03$ & 0.139 \\
\hline Time since onset (wk) & $3.63 \pm 4.87$ & $3.57 \pm 3.43$ & 0.950 \\
\hline MMSE-K & $25.00 \pm 3.32$ & $26.04 \pm 3.17$ & 0.188 \\
\hline Berg Balance Scale & $17.24 \pm 18.80$ & $16.56 \pm 18.14$ & 0.878 \\
\hline NIHSS & $9.42 \pm 5.84$ & $9.86 \pm 6.67$ & 0.766 \\
\hline Best motor paretic arms & $2.48 \pm 1.41$ & $2.19 \pm 1.53$ & 0.408 \\
\hline Best motor non-paretic arms & $0.14 \pm 0.74$ & $0.05 \pm 0.31$ & 0.472 \\
\hline \multicolumn{4}{|l|}{ Jebsen Hand Function Test } \\
\hline Paretic hand & $19.59 \pm 23.78$ & $19.36 \pm 28.34$ & 0.975 \\
\hline Non-paretic hand & $73.96 \pm 20.23$ & $70.86 \pm 17.88$ & 0.569 \\
\hline Family status, married & $26(83.9)$ & $34(77.3)$ & 0.482 \\
\hline Education & & & 0.086 \\
\hline$\leq$ Middle school & $10(32.3)$ & $23(52.3)$ & \\
\hline$\geq$ High school & $21(67.7)$ & $21(47.7)$ & \\
\hline Employed & $4(22.2)$ & $6(21.4)$ & 0.267 \\
\hline \multicolumn{4}{|l|}{ Chronic comorbidity } \\
\hline Diabetes mellitus & $8(25.8)$ & $11(25.0)$ & 0.937 \\
\hline Hypertension & $13(41.9)$ & $13(29.5)$ & 0.774 \\
\hline Malignancy & $5(16.1)$ & $5(11.4)$ & 0.550 \\
\hline Cardiac & $3(9.7)$ & $9(20.5)$ & 0.210 \\
\hline Musculoskeletal problem & $10(32.3)$ & $14(31.8)$ & 0.968 \\
\hline
\end{tabular}

Values are presented as mean \pm standard deviation or number (\%).

MMSE-K, Mini-Mental State Examination-Korean version; NIHSS, National Institutes of Health Stroke Scale.

${ }^{*} \mathrm{p}<0.05$, statistical significance.

Institutes of Health Stroke Scale (NIHSS), subscales of motor function in NIHSS, JHFT, marital status, education, employment, and accompanying chronic diseases (Table 1).

\section{SF-36 scores}

Comparison of the SF-36 scores in groups 1 and 2 revealed no statistically significant differences in the all subdomains and two main scores (PCS and MCS) (Fig. 2).

\section{$\mathrm{MBI}$ and $\mathrm{BDI}$ scores}

No significant difference in MBI activity score was found between groups 1 and 2 . The score for self-feeding was higher in group 2 than in group 1; however, the dif- ference was not statistically significant (Table 2).

Furthermore, we found no significant differences between the groups in BDI normal and mild-to-severe depression scores (Table 2).

\section{DISCUSSION}

We investigated the effect of dominant-hand paralysis on QOL of patients with subacute stroke. Our results indicate that paralysis of the dominant hand had no added effect on QOL in these patients, beyond the effect of stroke itself.

QOL encompasses several areas including physical functioning, psychological responses such as anxiety 


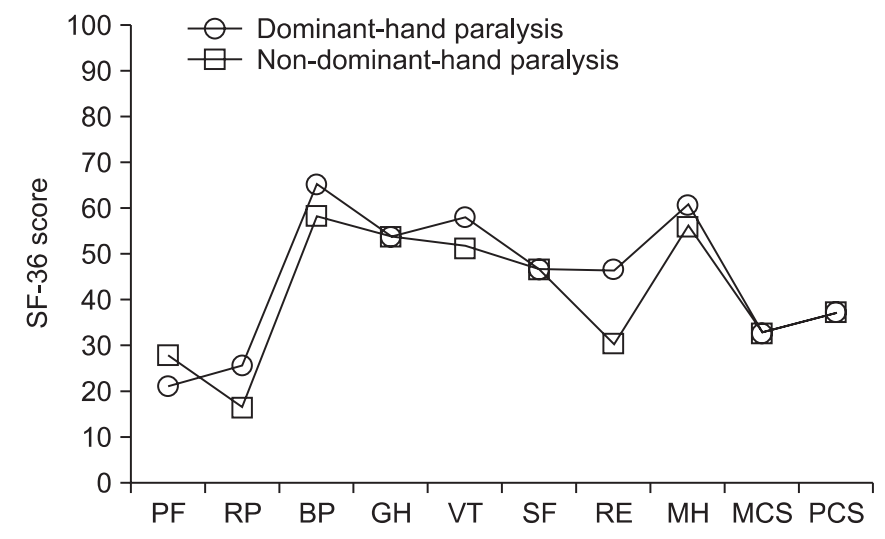

Fig. 2. Comparison of the physical and mental components of the SF-36 in the groups with paralysis of dominant hand $(\mathrm{n}=31$, circle $)$ and non-dominant hand $(\mathrm{n}=44$, square) revealed no significant differences between the groups. PF, physical function; RP, role physical; $\mathrm{BP}$, bodily pain; GH, general health; PCS, physical component summary; VT, vitality; SF, social function; RE, role emotional; MH, mental health; MCS, mental component summary. and depression, and social support. Assessment of QOL can be used for diagnosis, prognosis evaluation, patient monitoring, and treatment. Thus, the evaluation of QOL is of importance in clinical fields as well as in research $[25,26]$.

Several HRQOL instruments that assess the ability of a patient to perform a social role and gauge their wellbeing are available to clinicians [27]. The most widely used index, the SF-36, was designed to be a straightforward measure of function and stability in the medical outcomes study $[16,28]$. Therefore, we used the SF-36.

A comparison of QOL in patients whose dominant hand was affected by the stroke and in patients whose nondominant hand was affected revealed no significant differences between the groups in MCS, PCS, or any of the SF-36 subdomains.

Pyun et al. [4] found that ADL and depression were the two major factors affecting QOL after a stroke. We found no statistically significant differences between the groups in ADL using the MBI or in depression using the BDI. In addition, King [29] reported that the factors of social

Table 2. MBI and BDI scores in patients with paralysis in dominant- and non-dominant-hand following stroke

\begin{tabular}{|c|c|c|c|}
\hline & $\begin{array}{l}\text { Dominant-hand } \\
\text { paralysis }(n=31)\end{array}$ & $\begin{array}{l}\text { Non-dominant-hand } \\
\text { paralysis }(n=44)\end{array}$ & p-value* \\
\hline MBI total score & $43.58 \pm 23.31$ & $43.98 \pm 25.98$ & 0.946 \\
\hline Personal hygiene & $2.61 \pm 1.45$ & $2.75 \pm 1.42$ & 0.684 \\
\hline Bathing & $0.87 \pm 0.85$ & $1.09 \pm 1.22$ & 0.388 \\
\hline Feeding & $6.06 \pm 3.79$ & $7.59 \pm 3.66$ & 0.084 \\
\hline Toileting & $3.32 \pm 3.75$ & $3.61 \pm 3.79$ & 0.743 \\
\hline Stair climbing & $0.71 \pm 2.22$ & $0.34 \pm 1.43$ & 0.385 \\
\hline Dressing & $3.84 \pm 2.62$ & $3.86 \pm 2.61$ & 0.968 \\
\hline Bowel control & $7.39 \pm 3.48$ & $6.86 \pm 3.99$ & 0.557 \\
\hline Bladder control & $6.97 \pm 3.92$ & $6.55 \pm 4.31$ & 0.666 \\
\hline Ambulation & $4.00 \pm 4.40$ & $3.82 \pm 4.67$ & 0.865 \\
\hline Chair/bed transfers & $8.52 \pm 4.62$ & $7.48 \pm 5.09$ & 0.369 \\
\hline Total dependence $(0-20)$ & $7.00 \pm 8.53(n=4)$ & $6.67 \pm 6.00(n=9)$ & - \\
\hline Severe dependence (21-60) & $40.25 \pm 12.96(n=20)$ & $43.16 \pm 10.75(\mathrm{n}=25)$ & - \\
\hline Moderate dependence (61-90) & $70.83 \pm 9.15(n=6)$ & $76.13 \pm 5.74(\mathrm{n}=8)$ & - \\
\hline Slight dependence (91-99) & $93.00 \pm 0.00(n=1)$ & $93.50 \pm 2.12(\mathrm{n}=2)$ & - \\
\hline BDI total score & $16.31 \pm 11.59$ & $16.50 \pm 11.87$ & 0.891 \\
\hline Normal (0-13) & $7.46 \pm 4.81(\mathrm{n}=16)$ & $7.15 \pm 3.96(n=22)$ & - \\
\hline Mild-severe (14-63) & $24.40 \pm 10.15(n=15)$ & $25.00 \pm 10.09(\mathrm{n}=22)$ & - \\
\hline
\end{tabular}

Values are presented as mean \pm standard deviation or number (\%).

MBI, Modified Barthel Index; BDI, Beck Depression Inventory.

${ }^{*} \mathrm{p}<0.05$, statistical significance. 
support, social class, age, and cardiovascular disease predicted QOL after stroke. We found no statistically significant differences between the groups for family status, education, employed, age, and chronic comorbidity. These findings may explain why we found no difference in QOL between the two groups.

Doan et al. [30] found that increasing upper limb disability were associated with diminishing HRQOL. This study showed that both groups have impairment in upper limb, according to the subscales of motor function in NIHSS and JHFT. There was also no statistically significant difference in subscales of motor function in NIHSS and JHFT between the two groups. It can be another explanation for the reason why there was no significant difference in QOL between the two groups in this study.

De Haan et al. [14] used the Sickness Impact Profile to compare QOL in patients with left and right hemisphere lesions. They found that, with the exception of increased speech pathology, patients with left hemisphere lesions had a higher QOL than those with right hemisphere lesions. The authors concluded that this finding reflected the fact that patients with right hemisphere lesions experienced left unilateral neglect, impaired awareness of the disease, and spatial disorientation. However, De Haan et al. [14] did not investigate hand dominance, and their subjects were chronic stroke patients who were assessed 6 months after the stroke. Our study included patients who had not undergone intensive rehabilitation shortly after stroke onset, as well as those who were right-handed and those who were left-handed. Thus, the methodological differences do not allow the comparison of our results with those of De Haan et al. [14].

Pyun et al. [4] used the Quality of Life Index to compare QOL in chronic stroke patients with right and left hemiparesis after 6 months. They found no difference in QOL between patients with right and left hemiparesis, which is consistent with the previous studies reporting no relationship between QOL and the location of lesion in the brain [29]. However, Pyun et al. [4] did not compare the effect of paralysis of the dominant and non-dominant hands, and their subjects were in the chronic phase not the subacute phase of stroke.

Several studies have found deficits in the strength and dexterity of the uninvolved hand, although the deficit is minor compared to that in the hemiplegic side. The patients largely depend on the uninvolved hand to function in daily life, and the more severe the hemiparesis is the greater the level of dependency [31].

Harris and Eng [7] investigated whether the impairment in patients with chronic stroke was affected by the involvement of dominant hand. They found less impairment when the dominant hand was involved, compared to the involvement of the non-dominant hand. However, there was no effect of dominance on the use of paretic arm or on the performance of ADL. Thus, although dominance had a positive effect on the impairment, it did not translate into better arm performance in ADL.

Moreover, Harris and Eng [7] found that the scores on functions of individuals whose dominant hand was affected were no different from those of patients whose non-dominant hand was affected. The authors concluded that for more complex tasks (e.g., dressing, eating, and bathing), individuals with stroke may use compensatory strategies, such as using adaptive equipment, thus minimizing the effect of hand dominance. Furthermore, bimanual movement and coordination in ADL tasks are often used, and the required contribution of the dominant hand is not as substantial compared to unilateral tasks. These findings may explain why we found no difference in MBI scores between the groups.

After stroke, $25 \%$ to $75 \%$ of the patients reported of experiencing depression, which is one of the major predictors of total QOL [32]. We assessed depression using the BDI at an average of $3.59 \pm 4.06$ weeks after stroke and found no significant difference between the patients with paralysis on dominant and non-dominant hands. Several meta-analyses have found no correlation between brain lesion location and depression [32,33]. Nelson et al. [34] reported that time was an important factor for depression. They compared depression in patients with left and right hemisphere lesions at 2 weeks, 2 months, and 6 months after stroke and found that although depression resolved in patients with right hemisphere lesions after 2 months, they experienced more recurrence at 6 months compared to the patients with left hemisphere lesions. Our finding is consistent with that of Nelson et al. [34], which indicates that there was no difference in occurrence of depression between the groups at the subacute stage of stroke.

However, caution must be taken in generalizing our results because our sample was restricted to subacute patients who were studied 3 months after the stroke. Also, 
the patients with chronic stroke were not considered in our study. Moreover, some statistically significant results may have been overlooked due to the small sample size of the dominant-hand group. Finally, the NIHSS score for the patients in our study was lower than that in the general stroke population, indicating that our patients had relatively mild strokes. Further studies that include a larger sample of patients with dominant left hands, patients with chronic stroke, and a wider range of functional impairment are needed to confirm and extend our results.

In conclusion, we investigated whether the paralysis of dominant hand affected QOL in patients with subacute stroke. We found no significant differences in QOL, $\mathrm{ADL}$, or depression between patients with paralysis of the dominant hand and those with paralysis of the nondominant hand. Thus, we conclude that in comparison to the paralysis of non-dominant hand, the paralysis of dominant hand may not be an important factor for QOL in patients with mild subacute stroke.

\section{CONFLICT OF INTEREST}

No potential conflict of interest relevant to this article was reported.

\section{REFERENCES}

1. Han B, Haley WE. Family caregiving for patients with stroke: review and analysis. Stroke 1999;30:1478-85.

2. Jonsson AC, Lindgren I, Hallstrom B, Norrving B, Lindgren A. Determinants of quality of life in stroke survivors and their informal caregivers. Stroke 2005; 36:803-8.

3. Black-Schaffer RM, Osberg JS. Return to work after stroke: development of a predictive model. Arch Phys Med Rehabil 1990;71:285-90.

4. Pyun SB, Kim SH, Hahn MS, Kwon HK, Lee HJ. Quality of life after stroke. J Korean Acad Rehabil Med 1999; 23:233-9.

5. Triggs WJ, Calvanio R, Levine M, Heaton RK, Heilman KM. Predicting hand preference with performance on motor tasks. Cortex 2000;36:679-89.

6. Provins KA. The specificity of motor skill and manual asymmetry: a review of the evidence and its implications. J Mot Behav 1997;29:183-92.
7. Harris JE, Eng JJ. Individuals with the dominant hand affected following stroke demonstrate less impairment than those with the nondominant hand affected. Neurorehabil Neural Repair 2006;20:380-9.

8. Annett M. Five tests of hand skill. Cortex 1992;28:583600.

9. Bestelmeyer PE, Carey DP. Processing biases towards the preferred hand: valid and invalid cueing of leftversus right-hand movements. Neuropsychologia 2004;42:1162-7.

10. Kauranen K, Vanharanta H. Influences of aging, gender, and handedness on motor performance of upper and lower extremities. Percept Mot Skills 1996;82:51525.

11. Gowland C, deBruin H, Basmajian JV, Plews N, Burcea I. Agonist and antagonist activity during voluntary upper-limb movement in patients with stroke. Phys Ther 1992;72:624-33.

12. Spaulding SJ, McPherson JJ, Strachota E, Kuphal M, Ramponi M. Jebsen Hand Function Test: performance of the uninvolved hand in hemiplegia and of righthanded, right and left hemiplegic persons. Arch Phys Med Rehabil 1988;69:419-22.

13. Laufer Y, Gattenio L, Parnas E, Sinai D, Sorek Y, Dickstein R. Time-related changes in motor performance of the upper extremity ipsilateral to the side of the lesion in stroke survivors. Neurorehabil Neural Repair 2001;15:167-72.

14. De Haan RJ, Limburg M, Van der Meulen JH, Jacobs HM, Aaronson NK. Quality of life after stroke: impact of stroke type and lesion location. Stroke 1995;26:4028.

15. McMeekan ER, Lishman WA. Retest reliabilities and interrelationship of the Annett hand preference questionnaire and the Edinburgh Handedness Inventory. Br J Psychol 1975;66:53-9.

16. Han CW, Lee EJ, Iwaya T, Kataoka H, Kohzuki M. Development of the Korean version of Short-Form 36Item Health Survey: health related QOL of healthy elderly people and elderly patients in Korea. Tohoku J Exp Med 2004;203:189-94.

17. Ware JE Jr. SF-36 health survey update. Spine (Phila Pa 1976) 2000;25:3130-9.

18. Goulding MR, Rogers ME, Smith SM. Public health and aging: trends in aging: United States and worldwide. JAMA 2003;289:1371-3. 
19. Jung HY, Park BK, Shin HS, Kang YK, Pyun SB, Paik NJ, et al. Development of the Korean version of Modified Barthel Index (K-MBI): multi-center study for subjects with stroke. J Korean Acad Rehabil Med 2007;31:28397.

20. Kim WH, Hahn SJ, Im HJ, Yang KS. Reliability and validity of the Korean World Health Organization Quality of Life (WHOQOL)-BREF in people with physical impairments. Ann Rehabil Med 2013;37:488-97.

21. Jang SH, Rah UW, Kim YC, Park YS, Jo D, Kim YC, et al. Development of Korean Academy of Medical Sciences guideline-rating the impairment in pain. J Korean Med Sci 2009;24 Suppl 2:S330-7.

22. Kim HJ, Park EH. Diagnostic efficiency of BDI in a clinical setting: comparison among depression, anxiety, psychosis and control group. Int J Innov, Managd Technol 2010;1:502-6.

23. Hahn HM, Yum TH, Shin YW, Kim KH, Yoon DJ, Chung KJ. A standardization study of Beck Depression Inventory in Korea. J Korean Neuropsychiatr Assoc 1986;25:487-500.

24. Beck AT. Psychometric properties of the Beck Depression Inventory: twenty-five years of evaluation. Clin Psychol Rev 1988;8:77-100.

25. Perry S, Kowalski TL, Chang CH. Quality of life assessment in women with breast cancer: benefits, acceptability and utilization. Health Qual Life Outcomes 2007;5:24.
26. Donaldson MS. Taking stock of health-related qualityof-life measurement in oncology practice in the United States. J Natl Cancer Inst Monogr 2004;(33):155-67.

27. Wang HM, Beyer M, Gensichen J, Gerlach FM. Healthrelated quality of life among general practice patients with differing chronic diseases in Germany: cross sectional survey. BMC Public Health 2008;8:246.

28. Coons SJ, Rao S, Keininger DL, Hays RD. A comparative review of generic quality-of-life instruments. Pharmacoeconomics 2000;17:13-35.

29. King RB. Quality of life after stroke. Stroke 1996;20: 1467-72.

30. Doan QV, Brashear A, Gillard PJ, Varon SF, Vandenburgh AM, Turkel CC, et al. Relationship between disability and health-related quality of life and caregiver burden in patients with upper limb poststroke spasticity. PM R 2012;4:4-10.

31. Han TR, Yoon KJ, Jung SH. The chronological review of uninvolved hand function in stroke patients. J Korean Acad Rehabil Med 2004;28:13-9.

32. Hadidi N, Treat-Jacobson DJ, Lindquist R. Poststroke depression and functional outcome: a critical review of literature. Heart Lung 2009;38:151-62.

33. Robinson RG, Spalletta G. Poststroke depression: a review. Can J Psychiatry 2010;55:341-9.

34. Nelson LD, Cicchetti D, Satz P, Sowa M, Mitrushina M. Emotional sequelae of stroke: a longitudinal perspective. J Clin Exp Neuropsychol 1994;16:796-806. 